\title{
An active core-shell nanoscale design for high voltage cathode of lithium storage devices
}

Zhongpei $\mathrm{Lu}^{1}$, Yang $\mathrm{Liu}^{1}$, Xiaojun $\mathrm{Lu}^{1}$, Hao Wang ${ }^{1}$, Gang Yang ${ }^{1 *}$, Yimin $\mathrm{Chao}^{2 *}$, Fan Yin ${ }^{1}$, Weili Li, and Xuefan Jiang ${ }^{1}$

${ }^{1}$ Jiangsu Laboratory of Advanced Functional Material, School of Chemistry and Materials Engineering, Changshu Institute of Technology, Changshu 215500, P. R. China

${ }^{2}$ Energy Materials Laboratory, School of Chemistry, University of East Anglia, Norwich NR4 7TJ, UK

* To whom correspondence should be addressed:

E-mail: gyang@cslg.edu.cn (GY)

y.chao@uea.ac.uk (YC) 
Abstract: Spinel $\mathrm{LiNi}_{0.5} \mathrm{Mn}_{1.5} \mathrm{O}_{4}(\mathrm{LNM})$ is a potential high-voltage cathode for commercial lithium-ion batteries (LIBs). Maintaining an appropriate amount of $\mathrm{Mn}^{3+}$ in $\mathrm{LNM}$ is necessary to improve the rate performance. However, $\mathrm{Mn}^{3+}$ dissolution in the interface of $\mathrm{LNM}$ and electrolyte leads to the fast capacity degradation. Therefore, designing a cathode to prevent $\mathrm{Mn}^{3+}$ loss during charge/discharge is important for high performance LIBs. Here we present an active core-shell design with coating another high-voltage cathode material $\mathrm{LiCoPO}_{4}$ (LCP) on the surface of LNM nanoparticles. The LCP layer can simultaneously induce $\mathrm{Mn}^{3+}$ ions at the interface between LCP and LNM, and act as a stable shell to prevent the loss of $\mathrm{Mn}^{3+}$. The optimized sample LNM@5\%LCP possesses $128 \mathrm{mAh} \mathrm{g}^{-1}$ at $0.5 \mathrm{C}$ and $115 \mathrm{mAh} \mathrm{g}^{-1}$ at $20 \mathrm{C}$ rate, and maintains $96 \%$ of the initial capacity operated at $55^{\circ} \mathrm{C}$ over 100 cycles. 
High-performance lithium-ion batteries (LIBs) have been developed into promising energy storage devices for electric vehicles (EVs), hybrid electric vehicles (HEVs), and portable electronic devices ${ }^{1,2}$. Significant progresses have been made on materials for cathode, which is still one of the shortcomings in electric vehicle applications ${ }^{3,4}$. In recent years, high-voltage spinel $\mathrm{LiNi}_{0.5} \mathrm{Mn}_{1.5} \mathrm{O}_{4}$ is considered as one of the most potential cathode materials for LIBs. $\mathrm{LiNi}_{0.5} \mathrm{Mn}_{1.5} \mathrm{O}_{4}$ has a voltage plateau at $4.7 \mathrm{~V}$, making the energy density up to $650 \mathrm{Wh} \mathrm{kg}^{-1}$, which is much higher than those in other cathode materials such as $\mathrm{LiCoO}_{2}\left(\sim 460 \mathrm{Wh} \mathrm{kg}^{-1}\right), \mathrm{LiMn}_{2} \mathrm{O}_{4}\left(\sim 400 \mathrm{Wh} \mathrm{kg}^{-1}\right), \mathrm{LiFePO}_{4}\left(\sim 495 \mathrm{Wh} \mathrm{kg}^{-1}\right)$, $\mathrm{LiNi}_{0.5} \mathrm{Co}_{0.3} \mathrm{Mn}_{0.2} \mathrm{O}_{2}\left(\sim 550 \mathrm{Wh} \mathrm{kg}^{-1}\right)$, and $\mathrm{LiNi}_{1 / 3} \mathrm{Co}_{1 / 3} \mathrm{Mn}_{1 / 3} \mathrm{O}_{2}\left(\sim 576 \mathrm{Wh} \mathrm{kg}^{-1}\right)^{5-8}$.

$\mathrm{LiNi}_{0.5} \mathrm{Mn}_{1.5} \mathrm{O}_{4}$ is usually with two types of structures: ordered and disordered. The ordered spinel $(\mathrm{P} 4332)$ is well ordered in two distinct octahedral sites, $4 \mathrm{~b}$ sites for $\mathrm{Ni}(2+)$ and $12 \mathrm{~d}$ sites for $\mathrm{Mn}(4+)$. The disordered spinel (Fd-3m) includes $\mathrm{Ni}(2+) / \mathrm{Mn}(4+)$ randomly distributed in $16 \mathrm{~d}$ octahedral sites or the presence of $\mathrm{Mn}(3+) .{ }^{9,10}$ An appropriate amount of $\mathrm{Mn}^{3+}$ ions is one of the sensitive factors improving the electrochemical properties of $\mathrm{LiNi}_{0.5} \mathrm{Mn}_{1.5} \mathrm{O}_{4}{ }^{11-14} \cdot \mathrm{Mn}^{3+}$ ions in disordered spinel can increase the conductivity to approximately two orders of magnitude higher than that of ordered spinel ${ }^{11}$, although the rate performance of the spinel is not directly proportional to the $\mathrm{Mn}^{3+}$ content ${ }^{15}$. However, $\mathrm{Mn}^{3+}$ in disordered spinel leads to a side reaction that produces soluble $\mathrm{Mn}^{2+}$ dissolved in the electrolyte and causes significant capacity loss during cycling, especially at elevated temperatures ${ }^{16}$.

An appropriate amount of $\mathrm{Mn}^{3+}$ ensures the high rate performance of $\mathrm{LiNi}_{0.5} \mathrm{Mn}_{1.5} \mathrm{O}_{4}$, but the dissolution of $\mathrm{Mn}^{3+} / \mathrm{Mn}^{2+}$ results in the serious capacity fading. In order to resolve the contradictions, two interesting routes have been explored in surface modification to prevent the loss of $\mathrm{Mn}^{3+}$ and also prevent the oxidation of the electrolyte operated at very high voltage. The first one is forming cathode film during charging/discharging processes ${ }^{17,18}$. For example, 
Cresce et al reported a surface modification was used to decrease the aggressive side reaction of spinel occurred during sustained $4.7 \mathrm{~V}$ operation or in elevated temperature ${ }^{17}$. Xu et al reported an effect way that a novel electrolyte system utilizes additives for designed surface modification to generate a cathode passivation layer ${ }^{18}$. The second route is directly coating inorganic materials on $\mathrm{LiNi}_{0.5} \mathrm{Mn}_{1.5} \mathrm{O}_{4}$ during the step of material preparation, such as $\mathrm{Bi}_{2} \mathrm{O}_{3}$, $\mathrm{Al}_{2} \mathrm{O}_{3}, \mathrm{SiO}_{2}, \mathrm{AlPO}_{4}{ }^{18-22}$. Konishi et al build a stable functional protecting layer of $\mathrm{Li}_{3} \mathrm{PO}_{4}$ on the surface of $\mathrm{LiNi}_{0.5} \mathrm{Mn}_{1.5} \mathrm{O}_{4}$, which shows improved cycle performance ${ }^{21}$. Kim studied the effects of depositing ultrathin $(<1 \mathrm{~nm}) \mathrm{Al}_{2} \mathrm{O}_{3}$ layers on $\mathrm{LiNi}_{0.5} \mathrm{Mn}_{1.5} \mathrm{O}_{4}$ particles using atomic layer deposition. The coating layer of $\mathrm{Al}_{2} \mathrm{O}_{3}$ was significantly improving columbic efficiency and cycle performance through suppressing the self-discharge and dissolution of transition metals ${ }^{18}$. Gottfried's group reported a $\mathrm{Li}_{4} \mathrm{Ti}_{5} \mathrm{O}_{12}$ film was coated as buffer layer onto a $\mathrm{LiNi}_{0.5} \mathrm{Mn}_{1.5} \mathrm{O}_{4}$. Because $\mathrm{Mn}$ and $\mathrm{Ni}$ in the near-surface region diffused from the $\mathrm{LiNi}_{0.5} \mathrm{Mn}_{1.5} \mathrm{O}_{4}$ layer into the coating layer of $\mathrm{Li}_{4} \mathrm{Ti}_{5} \mathrm{O}_{12}$, the cycle performance of $\mathrm{Li}_{4} \mathrm{Ti}_{5} \mathrm{O}_{12}$ coated $\mathrm{LiNi}_{0.5} \mathrm{Mn}_{1.5} \mathrm{O}_{4}$ is still poor, $102 \mathrm{mAh} \mathrm{g}^{-1}$ at the $1^{\text {st }}$ cycle and only $60 \mathrm{mAh} \mathrm{g}^{-1}$ at the $100^{\text {th }}$ cycle $^{22}$.

Considering both high rate performance and high reversibility for lithium storage of $4.7 \mathrm{~V}$ cathode $\mathrm{LiNi}_{0.5} \mathrm{Mn}_{1.5} \mathrm{O}_{4}$, the coating material should play the roles in tuning the amount of $\mathrm{Mn}^{3+}$ and constructing an stable shell on $\mathrm{LiNi}_{0.5} \mathrm{Mn}_{1.5} \mathrm{O}_{4}$ to prevent the loss of $\mathrm{Mn}^{3+}$. Here we choose $\mathrm{LiCoPO}_{4}$, another $4.7 \mathrm{~V}$ cathode, as a stable shell for spinel, with the hypothesis that its inorganic nature and excellent chemical stability up to $4.7 \mathrm{~V}$ with organic electrolyte ensure a durable surface protection for $\mathrm{LNM}$ at high voltage. Olivine $\mathrm{LiCoPO}_{4}$, a polyanion material, is reported to have theoretical specific capacity of $170 \mathrm{mAh} \mathrm{g}{ }^{-1}$ at a discharge plateau near $4.8 \mathrm{~V}^{23-26}$. The growth of $\mathrm{LiCoPO}_{4}$ as coating layer is to induce the appearance of $\mathrm{Mn}^{3+}$ in $\mathrm{LiNi}_{0.5} \mathrm{Mn}_{1.5} \mathrm{O}_{4}$ during the synthesis; moreover $\mathrm{LiCoPO}_{4}$ thin layer can contribute to enhancing capacity by utilizing nanosized particles ${ }^{27-29}$ 
In this work, a spherical core-shell structure of high-voltage cathode material with $\mathrm{LiNi}_{0.5} \mathrm{Mnn}_{1.5} \mathrm{O}_{4}$ (core) and $\mathrm{LiCoPO}_{4}$ (shell) is designed and a series of composites LNM@x\%LCP $(x=1,5,10$ weight ratio) has been synthesized by one-pot hydrothermal method. The optimized sample LNM@5\%LCP has achieved a reversible capacity 128 mAh $\mathrm{g}^{-1}$ at $0.5 \mathrm{C}$ and $115 \mathrm{mAh} \mathrm{g}^{-1}$ at $20 \mathrm{C}$ rate $\left(1 \mathrm{C}=150 \mathrm{mAh} \mathrm{g}^{-1}\right)$. Furthermore, even operated at $55{ }^{\circ} \mathrm{C}$ for 100 cycles, $96 \%$ of the initial capacity has been retained with sample LNM@5\%LCP. The results have successfully demonstrated that $\mathrm{LiCoPO}_{4}$ shell plays the following important roles: (1) inducing $\mathrm{Mn}^{3+}$ between the interface of $\mathrm{LiNi}_{0.5} \mathrm{Mn}_{1.5} \mathrm{O}_{4}$ and $\mathrm{LiCoPO}_{4}$, (2) preventing $\mathrm{Mn}^{3+}$ dissolution during charge and discharge cycles, (3) inhibiting the decomposition of electrolyte $\mathrm{LiPF}_{6}$ due to the common-ion effect.

\section{Results and Discussion}

Synthesis of LNM@ $\boldsymbol{x} \%$ LCP. Schematic preparation procedure for $\mathrm{LiCoPO}_{4}$ coated $\mathrm{LiNi}_{0.5} \mathrm{Mn}_{1.5} \mathrm{O}_{4}$ is shown in Figure 1. The as-produced $\mathrm{LiNi}_{0.5} \mathrm{Mn}_{1.5} \mathrm{O}_{4}$ sample is consistent of porous spherical micrometer scale particles. Each spherical LNM particle is composed by ordered self-assembled nanocrystals and full of flowable space. The facile hydrothermal method is employed to prepare LNM@x\%LCP because the abundant flowable space within the porous structure of LNM is conducive for the transportation of the ions of $\mathrm{Li}^{+}, \mathrm{Co}^{2+}$ and $\mathrm{PO}_{4}{ }^{3-}$ to produce $\mathrm{LiCoPO}_{4}$ shell coated on the primary nanocrystals of $\mathrm{LiNi}_{0.5} \mathrm{Mn}_{1.5} \mathrm{O}_{4}$.

The SEM and TEM images of LNM@5\%LCP spherical particles show the surface morphology and the sectional views after the particles crashed into half (Figure 1a-1f). LNM@5\%LCP samples present homogeneous spherical morphologies with particle diameters in the region of 5-8 $\mu \mathrm{m}$ (Figure 1a). Each spherical micrometer scale particle is covered by numerous nanoparticles of diameter $\sim 80 \mathrm{~nm}$ (Figure 1b and Figure S1 in Supplementary). From the sectional view of LNM@5\%LNM, one can see that the spherical micrometer particle is porous and full of flowable space (Figure 1c and 1d). The porous spherical 
morphologies are also presented in samples of LNM@1\%LCP and LNM@10\%LCP (Figure $\mathrm{S} 2$ in Supplementary). The porous structure of spherical $\mathrm{LiNi}_{0.5} \mathrm{Mn}_{1.5} \mathrm{O}_{4}$ is useful for the efficient contact with electrolyte and providing the channels for lithium diffusion during charge/discharge processes. TEM images show the tough surface of a LNM@5\%LCP particle (Figure 1e), and a very thin LCP coating layer is visible on the surface of primary LNM particle (in Figure 1f).

The elemental distribution and composition on the surface and cross-section of LNM@5\%LCP are analyzed by energy dispersive spectroscopy (EDS) shown in Figure 2, where Ni, Mn, Co and P can be identified clearly. The distribution of Co and P are complete and uniform on the particle surface and all over the cross-section of LNM@5\%LCP particles, indicating a homogeneous formation of nano-LCP coating layer. Similar results from LNM@1\%LCP and LNM@10\%LCP are also observed, as shown in Figure S3 in Supplementary.

The powder XRD patterns of the pure $\mathrm{LiNi}_{0.5} \mathrm{Mn}_{1.5} \mathrm{O}_{4}$ and the composites LNM@ $1 \% \mathrm{LCP}$, LNM@5\%LCP, and LNM@10\%LCP are displayed in Figure 3. All the peaks in the XRD patterns are well matched with $\mathrm{LiNi}_{0.5} \mathrm{Mn}_{1.5} \mathrm{O}_{4}$ phase (JCPDS 80-2162). The enlarged XRD patterns (the inset in Figure 3) show weak characteristic peaks of $\mathrm{LiCoPO}_{4}(\mathrm{JCPDS} 32-0552)$ indexed by (101) at $22.4^{\circ}$ and (020) at $30.8^{\circ}$ from samples LNM@5\%LCP and LNM@10\% LCP ${ }^{30}$. The ICP and specific surface area for the samples are summarized in Table 1. The absolute moles of $\mathrm{Mn}$ and Ni elements in pure LNM and composites LNM@x\%LCP are all resided within proper range from ICP results and the amounts of Co and $\mathrm{P}$ are changed concurrently with the stated quantity of $\mathrm{LiCoPO}_{4}$ (Table 1). Owing to similar porous spherical morphologies appeared in the four samples, the specific surface area values are very close, $6.67 \mathrm{~m}^{2} \mathrm{~g}^{-1}$ in pure LNM, 5.89, 5.22 and $4.80 \mathrm{~m}^{2} \mathrm{~g}^{-1}$ in LNM@ $1 \% \mathrm{LCP}$, LNM@5\%LCP and LNM@10\%LCP, respectively. 
$\mathrm{Mn}^{3+}$ on the spinel induced by $\mathrm{LiCoPO}_{4}$ shell. The residual amount of $\mathrm{Mn}^{3+}$ in spinel $\mathrm{LiNi}_{0.5} \mathrm{Mn}_{1.5} \mathrm{O}_{4}$ is one of the important factors affecting the rate and cyclic performance ${ }^{11-14} . \mathrm{In}$ this work, $\mathrm{Mn}^{3+}$ in the starting spinel $\mathrm{LiNi}_{0.5} \mathrm{Mn}_{1.5} \mathrm{O}_{4}$ is reduced to a very low value through re-annealing at $700^{\circ} \mathrm{C}$ for 10 hours (Table 1), but a considerable amount of $\mathrm{Mn}^{3+}$ in $\mathrm{LiNi}_{0.5} \mathrm{Mn}_{1.5} \mathrm{O}_{4} @ x \% \mathrm{LiCoPO}_{4}$ has been detected by initial discharge profiles and XPS measurement, respectively.

A characteristic discharge plateau at $4.0 \mathrm{~V}$ is a sensitive index to estimate the sum content of $\mathrm{Mn}^{3+}$ in the spinel $\mathrm{LiNi}_{0.5} \mathrm{Mn}_{1.5} \mathrm{O}_{4}{ }^{11,14,31}$. The sum of $\mathrm{Mn}^{3+}$ in pure LNM, LNM@1\%LCP, LNM@5\%LCP and LNM@10\%LCP is 0, 1.05\%, 6.31\% and 10.86\%, respectively (listed in Table 1), according to the capacity contribution from 4.0 V discharge plateau (Figure S4 in Supplementary). The sum of $\mathrm{Mn}^{3+}$ observed in $\mathrm{LiNi}_{0.5} \mathrm{Mn}_{1.5} \mathrm{O}_{4} @ x \% \mathrm{LiCoPO}_{4}$ increases concurrently with the increasing amount of $\mathrm{LiCoPO}_{4}$ shell.

It is well known that XPS is a powerful method to study the elemental state located on the crystal surface. The high resolution Co2p spectra (Figure S5a in Supplementary) show a strong peak at binding energy of $781 \mathrm{eV}$, which can be attributed to $\mathrm{Co}^{2+}$ in $\mathrm{LiCoPO}_{4}$, and $\mathrm{P} 2 \mathrm{p}$ (Figure S3b in Supplementary) observed at $133.5 \mathrm{eV}$ corresponds to the $\mathrm{P}^{5+}$ state in $\mathrm{LiCoPO}_{4}$ 35. The high resolution XPS peaks in the region of Mn2p prove the mixed states of $\mathrm{Mn}^{3+}$ and $\mathrm{Mn}^{4+}$ in the samples as shown in Figure 4. According to the fittings, the surface $\mathrm{Mn}^{3+}$ in $\mathrm{LNM}$, LNM@1\%LCP, LNM@5\%LCP and LNM@10\%LCP is calculated about 18.1\%, 27.0\%,34.9\% and $45.8 \%$ of the total amount of Mn element detected on the surface by XPS, respectively (Table 1). The percentages of $\mathrm{Mn}^{3+}$ recorded by XPS give the same trend increasing with the amount of $\mathrm{LiCoPO}_{4}$, but the values of $\mathrm{Mn}^{3+}$ are much higher than those calculated by $4.0 \mathrm{~V}$ plateau. $\mathrm{Mn}^{3+}$ of spinel induced by $\mathrm{LiCoPO}_{4}$ shell might be mainly existed in the interface between $\mathrm{LiCoPO}_{4}$ and $\mathrm{LiNi}_{0.5} \mathrm{Mn}_{1.5} \mathrm{O}_{4}$ phases, but the reason why $\mathrm{Mn}^{3+}$ on spinel can be induced by $\mathrm{LiCoPO}_{4}$ is still unknown. In order to understand the oxidation states further, the 
high resolution XPS spectra in the region of Mn3s taken on LNM, LNM@1\%LCP, LNM@5\%LCP, LNM@10\%LCP, respectively, are displayed in Figure S6. The splitting between Mn3s peak and its satellite is related with the chemical state of Mn element. The average oxidation state (AOS) of $\mathrm{Mn}^{+\mathrm{AOS}}$ can be calculated by the following equation ${ }^{34,35}$ :

$$
\mathrm{AOS}=8.956-1.126 \Delta \mathrm{E}
$$

where $\Delta \mathrm{E}$ is the splitting energy in the peak fitting for Mn3s. The calculated AOS values are 4.03, 3.99, 3.88 and 3.79 for pure LNM, LNM@1\%LCP, LNM@5\%LCP and LNM@10\%LCP, respectively.

Cyclic voltammetry $(\mathrm{CV})$ profile is another technique to demonstrate the appearance and amount of $\mathrm{Mn}^{3+}$ in LNM. Figure 5 shows the redox processes of pure LNM and the composites LNM@x\%LCP. In the CV curve of pure LNM, only one pair of redox peaks are presented at the potentials of $4.65 / 4.83 \mathrm{~V}$, which are associated with the oxidation/reduction of $\mathrm{Ni}^{2+} / \mathrm{Ni}^{4+}$ (Figure 5a). After LCP coating, a couple of extra peaks near $4.0 \mathrm{~V}$ are clearly appeared in the composites, which are "fingerprint peaks" of the redox related with $\mathrm{Mn}^{3+}$, 4.02/3.97 V in LNM@5\%LCP and 4.04/3.97 V in LNM@10\%LCP. It is worth noting that the peaks close to $4.0 \mathrm{~V}$ related with $\mathrm{Mn}^{3+}$ become stronger and stronger along with the increased amount of $\mathrm{LiCoPO}_{4}$. It is the evidence that $\mathrm{Mn}^{3+}$ is induced by $\mathrm{LiCoPO}_{4}$ shell and changes concurrently with the amount of $\mathrm{LiCoPO}_{4}$. Moreover, the peaks close to $4.8 / 4.6 \mathrm{~V}$ are split to double features, which are assigned to $\mathrm{Ni}^{2+} / \mathrm{Ni}^{3+}$ and $\mathrm{Ni}^{3+} / \mathrm{Ni}^{4+}$ respectively, because the conductivity of LNM is increased upon the appearance of $\mathrm{Mn}^{3+}$.

Electrochemical properties. The schematic interface structure of $\mathrm{LiNi}_{0.5} \mathrm{Mn}_{1.5} \mathrm{O}_{4} @ \mathrm{LiCoPO}_{4}$ is shown in Figure 6a. While spherical particles of LNM@ $x \%$ LCP as cathode adhered to current collector using the polymeric binder of $\mathrm{PVDF}, \mathrm{LiCoPO}_{4}$ shell has direct contact with electrolyte (EL), which has hindered the dissolution of $\mathrm{Mn}^{3+}$ from spinel. The following four components are involved in the composite LNM@x\%LCP: (1) the interface between 
electrolyte (EL) and $\mathrm{LiCoPO}_{4}$, (2) the shell of $\mathrm{LiCoPO}_{4}$ phase, (3) the interface between $\mathrm{LiCoPO}_{4}$ and $\mathrm{LiNi}_{0.5} \mathrm{Mn}_{1.5} \mathrm{O}_{4}$, and (4) the core of LNMO phase. Lithium ions insertion and extraction have to go through them and different electrochemical performances are presented in the samples of LNM@1\%LCP, LNM@5\%LCP and LNM@10\%LCP, respectively. Electrochemical impedance spectra (EIS) and the relative fitting by equivalent circuit are powerful methods to simulate the electrochemical properties. The EIS of LNM@1\%LCP, LNM@5\%LCP and LNM@10\%LCP are plotted in Figure 6b and the fitted parameters are listed in Table S2. The equivalent circuits are proposed for the microstructures of LNM@ $x \%$ LCP in Figure 6c. $R_{\mathrm{S}}$ is the solution resistance of a cell, with a similar value in the three samples of LNM@ $x \%$ LCP. $R_{\mathrm{p}}$, the polarization resistance of Li ions through the interface between electrolyte (liquid) and $\mathrm{LiCoPO}_{4}$ (solid), is increased concurrently with the amount of $\mathrm{LiCoPO}_{4}$ shell, 66.35 ohms in LNM@1\%LCP, 197.4 ohms in LNM@5\%LCP and 202.6 ohms in LNM@10\%LCP, respectively, in line with the intrinsic poor conductivity of $\mathrm{LiCoPO}_{4} . R_{\mathrm{ct}}$, the charge transfer resistance happened at $\mathrm{LiCoPO}_{4}$ layer, is also increased concurrently with the amount of $\mathrm{LiCoPO}_{4}$ shell. $R_{\mathrm{p}}$, the resistance of lithium ions through the interface between $\mathrm{LiCoPO}_{4}$ shell and $\mathrm{LiNi}_{0.5} \mathrm{Mn}_{1.5} \mathrm{O}_{4}$ core, is in the same magnitude in the three samples because the existences of $\mathrm{Mn}^{3+}$ in the three samples render a good conductivity. $Z_{\mathrm{w}(\mathrm{LCP})}$ and $Z_{\mathrm{w}(\mathrm{LNM})}$ are the Warburg resistances of lithium ions transporting through $\mathrm{LiCoPO}_{4}$ shell and LNM core. Because the intrinsic conductivity of $\mathrm{LiCoPO}_{4}$ is much poorer than that of $\mathrm{LiNiPO}_{4}, Z_{\mathrm{w}}(\mathrm{LCP})$ is much higher than $Z_{\mathrm{w}}(\mathrm{LNM})$.

GITT technique based on chronopotentiometry directly reflects the diffusion ability of $\mathrm{Li}^{+}$during charge and discharge ${ }^{36}$. The $D_{\mathrm{Li}}{ }^{+}$values of pure LNM and composites of LNM@ $x \% \mathrm{LCP}$ are calculated and plotted in Figure $6 \mathrm{~d}-\mathrm{f}$. The lowest $D_{\mathrm{Li}}{ }^{+}$of each sample is appeared in the phase change of $\mathrm{Ni}^{2+} / \mathrm{Ni}^{4+}$. At $4.7 \mathrm{~V}$, the $D_{\mathrm{Li}}{ }^{+}$values of pure LNM and LNM@1\%LCP 
are much lower than those of LNM@5\%LCP and LNM@10\%LCP, confirming a certain amount of $\mathrm{Mn}^{3+}$ in the samples effectively improve the diffusion ability of $\mathrm{Li}^{+}$.

The initial specific capacities and cyclic stability of pure LNM, LNM@1\%LCP, LNM@5\%LCP and LNM@10\%LCP as cathode operated at $25{ }^{\circ} \mathrm{C}$ and $55{ }^{\circ} \mathrm{C}$, are compared in Figure 7. Pure LNM and LNM@1\%LCP deliver the initial capacities of 141 and 136 mAh $\mathrm{g}^{-1}$ at $0.5 \mathrm{C}$ rate, higher than $128 \mathrm{mAh} \mathrm{g}^{-1}$ in $\mathrm{LNM} @ 5 \% \mathrm{LCP}$ and $112 \mathrm{mAh}^{-1}$ in LNM@10\%LCP (Figure 7a). The sample LNM@10\%LNM, with highest amount of $\mathrm{LiCoPO}_{4}$, shows lowest initial specific capacity due to the intrinsic low conductivity of $\mathrm{LiCoPO}_{4}$. As shown in Figure S7 in Supplementary, the initial capacity is only $51 \mathrm{mAh} \mathrm{g}^{-1}$ for pure $\mathrm{LiCoPO}_{4}$. All the three samples give a $4.7 \mathrm{~V}$ discharge plateau, which is attributed to the redox of $\mathrm{Ni}^{2+} / \mathrm{Ni}^{4+}$. The other plateau near $4.0 \mathrm{~V}$ is observed corresponding to the "fingerprint" plateau reflected the redox reaction between the $\mathrm{Mn}^{3+}$ and $\mathrm{Mn}^{4+}$ couple. The $4.0 \mathrm{~V}$ plateau of the composite is another evidence that the amount of $\mathrm{Mn}^{3+}$ in spinel is concurrently increased with the increased amount of $\mathrm{LiCoPO}_{4}$ shell. Figure $7 \mathrm{~b}$ shows the cyclic stability of the samples. After 100 charge/discharge cycles, pure LNM and LNM@1\%LCP exhibit rapid capacity loss, only $58 \%$ and $64 \%$ of their initial capacity are remained, respectively. However, both samples LNM@5\%LCP and LNM@10\%LCP show excellent cyclic stability, $96 \%$ and $95 \%$ of their initial capacity are remained, respectively. At elevated temperature of $55^{\circ} \mathrm{C}$, LCP shell plays even more important role in maintaining electrochemical performance of LNM@x\%LCP samples (see Figure 7c and 7d). At the $100^{\text {th }}$ cycle, only $64 \%$ of its initial discharge capacity is remained in LNM@1\%LCP, but LNM@5\%LCP with the preferred shell presents the best performance, $96 \%$ of its initial discharge capacity $\left(120.9 \mathrm{mAh} \mathrm{g}^{-1}\right)$ is maintained. It can be concluded that $\mathrm{LiCoPO}_{4}$ shell does play a key role in ensuring the cyclic stability of LNM@x\%LCP samples. 
As mentioned above, the other important role of $\mathrm{LiCoPO}_{4}$ is to induce the appearance of $\mathrm{Mn}^{3+}$, which is useful in improving rate performance of LNM. Figure 8 shows the rate cyclic performance of the samples operated from $0.5 \mathrm{C}$ to $20 \mathrm{C}$ rate. At $20 \mathrm{C}$ rate, LNM@ $5 \% \mathrm{LCP}$ delivers the initial capacity of $115 \mathrm{mAh} \mathrm{g}^{-1}$ (Figure 8a), which is the highest value in comparison with $57 \mathrm{mAh} \mathrm{g}^{-1}$ of pure LNM, $87 \mathrm{mAh} \mathrm{g}{ }^{-1}$ of LNM@1\%LCP, and $92 \mathrm{mAh} \mathrm{g}^{-1}$ of LNM@10\%LCP. The polarization of LNM@5\%LCP electrode is the smallest within these four samples. It is observed that the rate capability of LNM@5\%LCP is far better than other samples (Figure $8 \mathrm{~b}$ and $8 \mathrm{c}$ ). Ragone plots of the four samples are shown in Figure 8d. The inverse relationship between specific energy density and specific power density is well established. Remarkably, LNM@5\%LCP electrode delivers a gravimetric energy density of 475.1 $\mathrm{Wh} \mathrm{kg}^{-1}$ while delivering a power density of $13.2 \mathrm{KW} \mathrm{kg}^{-1}$, much better than other samples.

The state of electrode and electrolyte after charge and discharge cycles. It is reported in literature that the $\mathrm{LiPF}_{6}$ of electrolyte worked at high voltage might be decomposed and deposited on electrode materials ${ }^{37-39}$. In order to analyze the surface changes of active materials, XPS spectra on the electrodes with pure LNM, LNM@1\%LCP, LNM@5\%LCP and LNM@10\%LCP charged/discharged after 100 cycles at $20 \mathrm{C}$ rate have been collected, see Figure 9. The P2p spectrum taken on the pure LNM electrode is clearly identified as two strong components (Figure 9a), $\mathrm{Li}_{x} \mathrm{PF}_{y}$ at $\sim 137.5 \mathrm{eV}$ and $\mathrm{Li}_{x} \mathrm{PO}_{y} \mathrm{~F}_{z}$ at $\sim 134.5 \mathrm{eV}$, respectively. This is consistent with the previous studies that an unwanted decomposition of the standard electrolyte, $\mathrm{LiPF}_{6}$, always happens on the surface of cathode with operating potentials over 4.5 $\mathrm{V}^{20,39,41}$. For the cycled electrode of LNM@1\%LCP, the minor P state is from $\mathrm{Li}_{x} \mathrm{PF}_{y}$ and the major $\mathrm{P}$ state is phosphate from the shell of $\mathrm{LiCoPO}_{4}$ (Figure 9b). For the both cycled electrodes of LNM@5\%LCP and LNM@10\%LCP, the P state from $\mathrm{Li}_{x} \mathrm{PF}_{y}$ is hardly to be detected (Figure 9c and 9d). It is clearly concluded that the $\mathrm{P}$ state from $\mathrm{PF}_{6}{ }^{-}$in the electrodes 
of LNM@x\%LCP is dramatically reduced with the increasing amount of $\mathrm{LiCoPO}_{4}$ shell. The percentages of $\mathrm{P}$ state of $\mathrm{Li}_{x} \mathrm{PF}_{y}$ are $4.86 \%, 0.05 \%$ and $0.03 \%$ of the total $\mathrm{P}$ detected in LNM@1\%LCP, LNM@5\%LCP and LNM@10\%LCP, respectively. It is evidenced that $\mathrm{LiCoPO}_{4}$ shell plays the roles in avoiding unwanted decomposition of electrolyte and improving the cyclic ability of $\mathrm{LiNi}_{0.5} \mathrm{Mn}_{1.5} \mathrm{O}_{4}$ operated at high voltage.

\section{Conclusion}

A novel series of composites $\mathrm{LiNi}_{0.5} \mathrm{Mn}_{1.5} \mathrm{O}_{4} @ x \% \mathrm{LiCoPO}_{4}(\mathrm{LNM} @ x \% \mathrm{LCP})$ have been synthesized and investigated as $4.7 \mathrm{~V}$ cathode for $\mathrm{LIBs}$. $\mathrm{LiCoPO}_{4}(\mathrm{LCP})$ as shell has been grown on the surface of $\mathrm{LiNi}_{0.5} \mathrm{Mn}_{1.5} \mathrm{O}_{4}$ (LNM) particles under hydrothermal condition. The growth of LCP has simultaneously induced $\mathrm{Mn}^{3+}$ on the interface of LCP and LNM, and the amount of $\mathrm{Mn}^{3+}$ increases with the growth of LCP shell. The appearance of $\mathrm{Mn}^{3+}$ has dramatically improved the conductivity and lithium diffusion ability of LNM. The sample LNM@5\%LCP has shown the best electrochemical properties, $128 \mathrm{mAh} \mathrm{g}^{-1}$ at $0.5 \mathrm{C}$ rate and $96 \%$ of its initial capacity remained after 100 cycles. At $20 \mathrm{C}$ rate, LNM@5\%LCP has demonstrated the best performance of $115 \mathrm{mAh} \mathrm{g}^{-1}$, much higher than $57 \mathrm{mAh} \mathrm{g}^{-1}$ of pure LNM. It can be concluded that an appropriate amount of $\mathrm{Mn}^{3+}$ is necessary for improving the capacity and rate performance, while the stable shell of LCP ensures the excellent cyclic stability of LNM@5\%LCP owing to its preventing the dissolution of $\mathrm{Mn}^{3+}$. It is worth noting that $\mathrm{LiCoPO}_{4}$ as a stable shell effectively reduces the decomposition of the electrolyte $\mathrm{LiPF}_{6}$ as well. The construction of active core@ stable shell is simple and applicable in preparing electrode materials for high-performance LIBs.

\section{Methods}

Synthesis of LiNio.5Mn1.5O4@LiCoPO4 nanoparticles. $\mathrm{LiNi}_{0.5} \mathrm{Mn}_{1.5} \mathrm{O}_{4} @ \mathrm{LiCoPO}_{4}$ was synthesized using one-pot hydrothermal method. Spherical $\mathrm{LiNi}_{0.5} \mathrm{Mn}_{1.5} \mathrm{O}_{4}$ particles as core were produced by co-precipitation (See details in Supplementary). $\mathrm{LiNi}_{0.5} \mathrm{Mn}_{1.5} \mathrm{O}_{4}$ particles 
were well dispersed in an aqueous solution of $\mathrm{Co}\left(\mathrm{NO}_{3}\right)_{2} \cdot 6 \mathrm{H}_{2} \mathrm{O}$ and $\mathrm{H}_{3} \mathrm{PO}_{4}$. After vigorous stirring for $2 \mathrm{~h}$, aqueous $\mathrm{LiOH}$ solution in the molar ratio of $\mathrm{Li}: \mathrm{Co}: \mathrm{P}$ set $2.0: 1.0: 1.0$ was placed into the mixture. The $\mathrm{pH}$ value of the mixture was adjusted to 8.5 by using ammonia. The final suspension was transferred into an autoclave and reacted for $10 \mathrm{~h}$ at $200{ }^{\circ} \mathrm{C}$. The black precipitate was centrifuged, washed for several times with distilled water and absolute ethyl alcohol, and finally dried at $60{ }^{\circ} \mathrm{C}$. In order to improve the crystallinity of $\mathrm{LiCoPO}_{4}$ shell, the precipitate was annealed at $700{ }^{\circ} \mathrm{C}$ for $10 \mathrm{~h}$ under air atmosphere. The as-synthesized composites with starting mass ratio of $\mathrm{LiCoPO}_{4}$ at $1 \%, 5 \%$ and $10 \%$ of $\mathrm{LiNi}_{0.5} \mathrm{Mn}_{1.5} \mathrm{O}_{4}$ in theoretical values, are simply named as LNM@1\%LCP, LNM@5\%LCP and LNM@10\%LCP, respectively. The real mass ratios of $\mathrm{LiCoPO}_{4}$ in the final composites were measured by ICP considering the yield of $\mathrm{LiCoPO}_{4}$ in hydrothermal condition. To study the morphologies, elemental state of the electrode and electrolyte decomposition after hundreds of charge/discharge cycles, cells were disassembled in an Ar-filled glove box. The components were rinsed for several times with dimethyl carbonates (DMC). The cathode was dried in Ar-filled glove box overnight prior to the XPS analysis.

Characterization. X-ray diffraction (XRD) measurements were carried out with a Rigaku diffractometer (Dmax-2200, Cu Ka radiation). A field-emission scanning electron microscope (FE-SEM, SIGMA, ZEISS, 20kV), and a transmission electron microscope (TEM, JEOL-2000CX, $200 \mathrm{kV}$ and HRTEM, JEOL-2010F, $200 \mathrm{kV}$ ) were employed to analyze the morphologies of samples. The composition and elemental state of the samples were analyzed by inductively coupled plasma (ICP) and X-ray photoelectron spectroscopy (XPS-ULVAC-PHI PHI 5000 Versa Probe spectrometer, Al Ka radiation, hv = $1486.6 \mathrm{eV}$ ).

Electrochemical test. Electrochemical performances of as-prepared samples were measured using CR2016 coin cells. The working electrode was a mixture of $80 \mathrm{wt} \%$ as-synthesized sample, $10 \mathrm{wt} \%$ acetylene black, and $10 \mathrm{wt} \%$ polyvinylidene difluoride binder in $\mathrm{N}$-methyl 
pyrrolidinone solvent. The slurry was casted on aluminum foil with mass loading of $c a 3 \mathrm{mg}$ $\mathrm{cm}^{-2}$, and dried at $100^{\circ} \mathrm{C}$ for $12 \mathrm{~h}$ under vacuum. The half-coin cell was assembled in an argon-filled glove box, using lithium metal as anode, Celgard 2500 as the separator, and $1 \mathrm{M}$ $\mathrm{LiPF}_{6}$ dissolved in ethylene carbonate and ethyl methyl carbonate (1:1 volume ratio) as the electrolyte. The assembled cell was galvanostatically cycled between 3.0 to $5.0 \mathrm{~V}$ at various current rates ranging from 0.5 to $20 \mathrm{C}\left(1 \mathrm{C}=150 \mathrm{mAh} \mathrm{g}^{-1}\right)$ by a LAND CT2001A battery test system. The working temperature for cell's cycling test was set at $25{ }^{\circ} \mathrm{C}$ and $55{ }^{\circ} \mathrm{C}$, respectively. All of the specific capacities were calculated on the basis of total mass of $\mathrm{LiNi}_{0.5} \mathrm{Mn}_{1.5} \mathrm{O}_{4} @ \mathrm{LiCoPO}_{4}$. Galvanostatic intermittent titration technique (GITT) was conducted at room temperature in the voltage range of 3.0-5.0 V. Cyclic voltammetry $(\mathrm{CV})$ tests were carried on PARSTAT2273 electrochemical workstation at the scanning rate of 0.1 $\mathrm{mV} \mathrm{s}^{-1}$ in the potential ranges from 3.0 to $5.0 \mathrm{~V}$ (vs. $\left.\mathrm{Li}^{+} / \mathrm{Li}\right)$. Electrochemical impedance spectroscopy (EIS) measurement was carried out by using PARSTAT2273 electrochemical workstation range from $100 \mathrm{kHz}$ to $10 \mathrm{mHz}$ with sinusoidal signal of $5 \mathrm{mV}$.

\section{Acknowledgements}

G.Y. would like to thank the financial support from the National Natural Science Foundation of China (Grant No. 51172032) and Natural Science Foundation of Jiangsu Province of China (Grant No. BK20141229).

\section{Author contributions}

G.Y. conceived the project. Z.P.L., Y.L., X.J.L. and G.Y. designed the experiments. C.F.D., H.W., Y.C., F.Y. and X.F.J. synthesized the samples, performed the experiments and analyzed the data. Z.P.L., Y.L., G.Y. and Y.C. wrote the manuscript.

\section{References}


[1] Larcher, D. \& Tarascon, J-M. Towards greener and more sustainable batteries for electrical energy storage. Nat. Chem. 7, 19-29 (2015).

[2] Tang, Y. X., Zhang, Y., Li, W. L., Ma, B. \& Chen, X. Rational material design for ultrafast rechargeable lithium-ion batteries. Chem. Soc. Rev. 44, 5926-5940 (2015).

[3] Andre, D. et al. Future generations of cathode materials: an automotive industry perspective. J. Mater. Chem. A 3, 6709-6732 (2015).

[4] Fan, X. et al. Pomegranate-structured conversion-reaction cathode with a built-in Li source for high-energy Li-ion batteries. ACS Nano 10, 5567-5577 (2016).

[5] Zhao, M. et al. Diphenyl disulfide as a new bifunctional film-forming additive for high-voltage $\mathrm{LiCoO}_{2}$ /graphite battery charged to 4.4V. J. Power Sources 323, 29-36 (2016).

[6] Yang, X. et al. High-performance aqueous asymmetric supercapacitor based on spinel $\mathrm{LiMn}_{2} \mathrm{O}_{4}$ and nitrogen-doped graphene/porous carbon composite. Electrochim. Acta 180, 287-294 (2015).

[7] Tian, R. et al. Drastically enhanced high-rate performance of carbon-coated $\mathrm{LiFePO}_{4}$ nanorods using a green chemical vapor deposition (CVD) method for lithium ion battery: A selective carbon coating process. ACS Appl. Mater. Interfaces 21, 11377-11386 (2015).

[8] Patoux, S. et al. High voltage spinel oxides for Li-ion batteries: From the material research to the application. J. Power Sources 189, 344-352 (2009).

[9] Chemelewski, K. R. \& Manthiram, A. Origin of site disorder and oxygen nonstoichiometry in $\mathrm{LiMn}_{1.5} \mathrm{Ni}_{0.5-\mathrm{x}} \mathrm{M}_{\mathrm{x}} \mathrm{O}_{4}(\mathrm{M}=\mathrm{Cu}$ and $\mathrm{Zn})$ cathodes with divalent dopant ions. J. Phys. Chem. C 117, 12465-12471 (2013).

[10] Xiao, J. el al. Interplay between two-phase and solid solution reactions in high voltage spinel cathode material for lithium ion batteries. J. Power Sources 242, 736-741 (2013).

[11] Xiao, J. et al. High- performance $\mathrm{LiNi}_{0.5} \mathrm{Mn}_{1.5} \mathrm{O}_{4}$ spinel controlled by $\mathrm{Mn}^{3+}$ concentration and site disorder. Adv. Mater. 24, 2109-2116 (2012). 
[12] Jafta, C. J., Mathe, M. K., Manyala, N., Roos, W. D. \& Ozoemena, K. I. Microwaveassisted synthesis of high-voltage nanostructured $\mathrm{LiNi}_{0.5} \mathrm{Mn}_{1.5} \mathrm{O}_{4}$ spinel: tuning the $\mathrm{Mn}^{3+}$ content and electrochemical performance. ACS Appl. Mater. Interfaces 5, 7592-7598 (2013).

[13] Gao, P. et al. Microwave rapid preparation of $\mathrm{LiNi}_{0.5} \mathrm{Mn}_{1.5} \mathrm{O}_{4}$ and the improved high rate performance for lithium-ion batteries. Electrochim. Acta 100, 125-132 (2013).

[14] Lee, J., Kim, C. \& Kang, B. High electrochemical performance of high-voltage $\mathrm{LiNi}_{0.5} \mathrm{Mn}_{1.5} \mathrm{O}_{4}$ by decoupling the $\mathrm{Ni} / \mathrm{Mn}$ disordering from the presence of $\mathrm{Mn}^{3+}$ ions. $N P G$ Asia Mater. 7, e211 (2015).

[15] Duncan, H., Hai, B., Leskes, M., Grey, C. P. \& Chen, G. Y. Relationships between Mn ${ }^{3+}$ content, structural ordering, phase transformation, and kinetic properties in $\mathrm{LiNi}_{\mathrm{x}} \mathrm{Mn}_{2-\mathrm{x}} \mathrm{O}_{4}$ cathode materials. Chem. Mater. 26, 5374-5382 (2014).

[16] Zheng, J. et al. Whittingham, M. S. \& Zhang, J.-G. Phys. Enhanced $\mathrm{Li}^{+}$ion transport in $\mathrm{LiNi}_{0.5} \mathrm{Mn}_{1.5} \mathrm{O}_{4}$ through control of site disorder. Chem. Chem. Phys. 14, 13515-13521 (2012).

[17] von Cresce, A. \& Xu, K. Electrolyte additive in support of $5 \mathrm{~V} \mathrm{Li}$ ion chemistry. $J$. Electrochem. Soc. 158, A337-342 (2011).

[18] Xu M.Q. et al. Development of novel lithium borate additives for designed surface modification of high voltage $\mathrm{LiNi}_{0.5} \mathrm{Mn}_{1.5} \mathrm{O}_{4}$ cathodes. Energy Environ. Sci. 9, 1308-1319 (2016).

[19] Shin, W.-K., Lee, Y.-S. \& Kim, D.-W. Study on the cycling performance of $\mathrm{LiNi}_{0.5} \mathrm{Mn}_{1.5} \mathrm{O}_{4}$ electrodes modified by reactive $\mathrm{SiO}_{2}$ nanoparticles. J. Mater. Chem. A 2, 6863-6869 (2014).

[20] Kim, J. W. et al. Surface chemistry of $\mathrm{LiNi}_{0.5} \mathrm{Mn}_{1.5} \mathrm{O}_{4}$ particles coated by $\mathrm{Al}_{2} \mathrm{O}_{3}$ using atomic layer deposition for lithium-ion batteries. J. Power Sources 274, 1254-1262 (2015).

[21] Konishi, H. et al. Effect of surface $\mathrm{Li}_{3} \mathrm{PO}_{4}$ coating on $\mathrm{LiNi}_{0.5} \mathrm{Mn}_{1.5} \mathrm{O}_{4}$ epitaxial thin film electrodes synthesized by pulsed laser deposition. J. Power Sources 269, 293-298 (2014). 
[22] Sachs, M. et al. $\mathrm{LiNi}_{0.5} \mathrm{Mn}_{1.5} \mathrm{O}_{4}$ high-voltage cathode coated with $\mathrm{Li}_{4} \mathrm{Ti}_{5} \mathrm{O}_{12}$ : a hard X-ray photoelectron spectroscopy (HAXPES) study. Phys. Chem. Chem. Phys. 17, 31790-31800 (2015).

[23] Truong, Q. D., Devaraju, M. K., Tomai, T. \& Honma, I. Direct observation of antisite defects in $\mathrm{LiCoPO}_{4}$ cathode materials by annular dark- and bright-field electron microscopy. ACS Appl. Mater. Interfaces 5, 9926-9932 (2013).

[24] Chen, L. et al. Relevance of $\mathrm{LiPF}_{6}$ as etching agent of $\mathrm{LiMnPO}_{4}$ colloidal nanocrystals for high rate performing Li-ion battery cathodes. ACS Appl. Mater. Interfaces 8, 4069-4075 (2016).

[25] Alyoshin, V. A., Pleshakov, E. A., Ehrenberg, H. \& Mikhailova, D. Platelike $\mathrm{LiMPO}_{4}$ (M $=\mathrm{Fe}, \mathrm{Mn}, \mathrm{Co}, \mathrm{Ni}$ ) for possible application in rechargeable $\mathrm{Li}$ ion batteries: Beyond nanosize . J. Phys. Chem. C 118, 17426-17435 (2014).

[26] Delacourt, C. et al. Toward understanding of electrical limitations (Electronic, Ionic) in $\mathrm{LiMPO}_{4}(\mathrm{M}=\mathrm{Fe}, \mathrm{Mn})$ electrode materials. J. Electrochem. Soc. 152, A913-A921 (2005).

[27] Yang, G. et al. The doping effect on the crystal structure and electrochemical properties of $\mathrm{LiMn}_{\mathrm{x}} \mathrm{M}_{1-\mathrm{x}} \mathrm{PO}_{4}(\mathrm{M}=\mathrm{Mg}, \mathrm{V}, \mathrm{Fe}, \mathrm{Co}, \mathrm{Gd})$, J. Power Sources 196, 4747-4755 (2011).

[28] Kreder, K.J., Assat, G. \& Manthiram, Microwave-assisted solvothermal synthesis of three polymorphs of $\mathrm{LiCoPO}_{4}$ and their electrochemical properties. Chem. Mater. 27, $5543-5549$ (2015).

[29] Truong, Q. D., Devaraju, M. K., Ganbe, Y., Tomai, T. \& Honma, I. Controlling the shape of $\mathrm{LiCoPO}_{4}$ nanocrystals by supercritical fluid process for enhanced energy storage properties. Sci. Rep. 4, 3975 (2014).

[30] Ni, J., Wang, H., Gao, L. \& Lu, L. A high-performance $\mathrm{LiCoPO}_{4} / \mathrm{C}$ core/shell composite for Li-ion batteries. Electrochim. Acta 70, 349-354 (2012). 
[31] Wan, L. et al. Ni/Mn ratio and morphology-dependent crystallographic facet structure and electrochemical properties of the high-voltage spinel $\mathrm{LiNi}_{0.5} \mathrm{Mn}_{1.5} \mathrm{O}_{4}$ cathode material. RSC Adv. 5, 25988-25997 (2015).

[32] Deng, Y. F., Zhao, S. X., Xu, Y. H., Gao, K. \& Nan, C. W. Impact of P-doped in spinel $\mathrm{LiNi}_{0.5} \mathrm{Mn}_{1.5} \mathrm{O}_{4}$ on degree of disorder, grain morphology, and electrochemical performance. Chem. Mater. 27, 7734-7742 (2015).

[33] Yang, S. F, Chen, J., Liu, Y. J. \& Yi, B. L. Preparing $\mathrm{LiNi}_{0.5} \mathrm{Mn}_{1.5} \mathrm{O}_{4}$ nanoplates with superior properties in lithium-ion batteries using bimetal-organic coordination-polymers as precursors. J. Mater. Chem. A 2, 9322-9330 (2014).

[34] Carabineiro, S. A. C. et al. Carbon monoxide oxidation catalysed by exotemplated manganese oxides. Catal. Lett. 134, 217 (2010).

[35] Rajalakshmi, A. et al. Physicochemical properties of $\mathrm{V}^{5+}$ doped $\mathrm{LiCoPO}_{4}$ as cathode materials for Li-ion batteries. J Sol-Gel Sci Technol. 65, 399-410 (2013).

[36] Jian, X.M. et al. Oxalic acid-assisted combustion synthesized $\mathrm{LiVO}_{3}$ cathode material for lithium ion batteries. J. Power Sources 246, 417-422 (2014).

[37] Markevich, E. et al. C. Reasons for capacity fading of $\mathrm{LiCoPO}_{4}$ cathodes in $\mathrm{LiPF}_{6}$ containing electrolyte solutions. Electrochem. Comm. 15, 22-25 (2012).

[38] Yan, G., Li, X., Wang, Z., Guo, H. \& Xiong, X. Beneficial effects of 1-propylphosphonic acid cyclic anhydride as an electrolyte additive on the electrochemical properties of $\mathrm{LiNi}_{0.5} \mathrm{Mn}_{1.5} \mathrm{O}_{4}$ cathode material. J. Power Sources 263, 231-238 (2014).

[39] Philippe, B. et al. Role of the LiPF6 salt for the long-term stability of silicon electrodes in Li-ion batteries - A photoelectron spectroscopy study. Chem. Mater. 25, 394-404 (2013). [40] Yan, G., Li, X., Wang, Z., Guo, H. \& Xiong, X. Beneficial effects of 1-propylphosphonic acid cyclic anhydride as an electrolyte additive on the electrochemical properties of $\mathrm{LiNi}_{0.5} \mathrm{Mn}_{1.5} \mathrm{O}_{4}$ cathode material. J. Power Sources 263, 231-238 (2014). 
[41] Song, Y.-M., Kim, C.-K., Kim, K.-E., Hong, S. Y., Choi, N.-S., Exploiting chemically and electrochemically reactive phosphite derivatives for high-voltage spinel $\mathrm{LiNi}{ }_{5.5} \mathrm{Mn}_{1.5} \mathrm{O}_{4}$ cathodes. J. Power Sources 302, 22-30 (2016). 
Table 1 | ICP results, physical parameters and the estimated $\mathrm{Mn}^{3+}$ percentage.

\begin{tabular}{|c|c|c|c|c|c|c|c|}
\hline & \multicolumn{4}{|c|}{ ICP /mol } & \multirow{2}{*}{$\begin{array}{l}\text { BET surface } \\
\text { area } / \mathrm{m}^{2} \mathrm{~g}^{-1}\end{array}$} & \multirow{3}{*}{$\begin{array}{l}\text { surface } \mathrm{Mn}^{3+} \\
\text { percentage } / \% \\
\text { a) }\end{array}$} & \multirow{3}{*}{$\begin{array}{c}\text { sum } \mathrm{Mn}^{3+} \\
\text { percentage } 1 \%\end{array}$} \\
\hline & Mn & $\mathrm{Ni}$ & Co & $\mathrm{P}$ & & & \\
\hline & & & & & & & \\
\hline LNM & 1.5 & 0.48 & I & I & 6.37 & 18.1 & I \\
\hline LNM@1\%LCP & 1.5 & 0.48 & 0.011 & 0.015 & 5.89 & 27.0 & 2.93 \\
\hline LNM@5\%LCP & 1.5 & 0.49 & 0.057 & 0.039 & 5.22 & 34.9 & 7.87 \\
\hline LNM@10\%LCP & 1.5 & 0.47 & 0.106 & 0.092 & 4.80 & 45.8 & 14.9 \\
\hline
\end{tabular}




\section{Schematic}

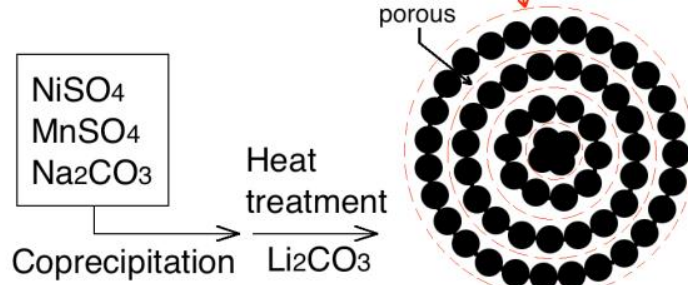

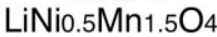

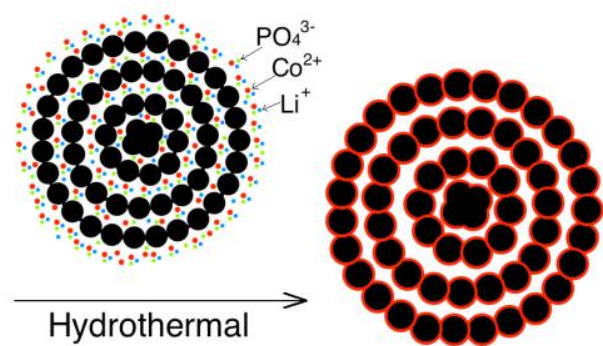

$\mathrm{LiCoPO}_{4}$ coated LiNio.5Mn1.5O4
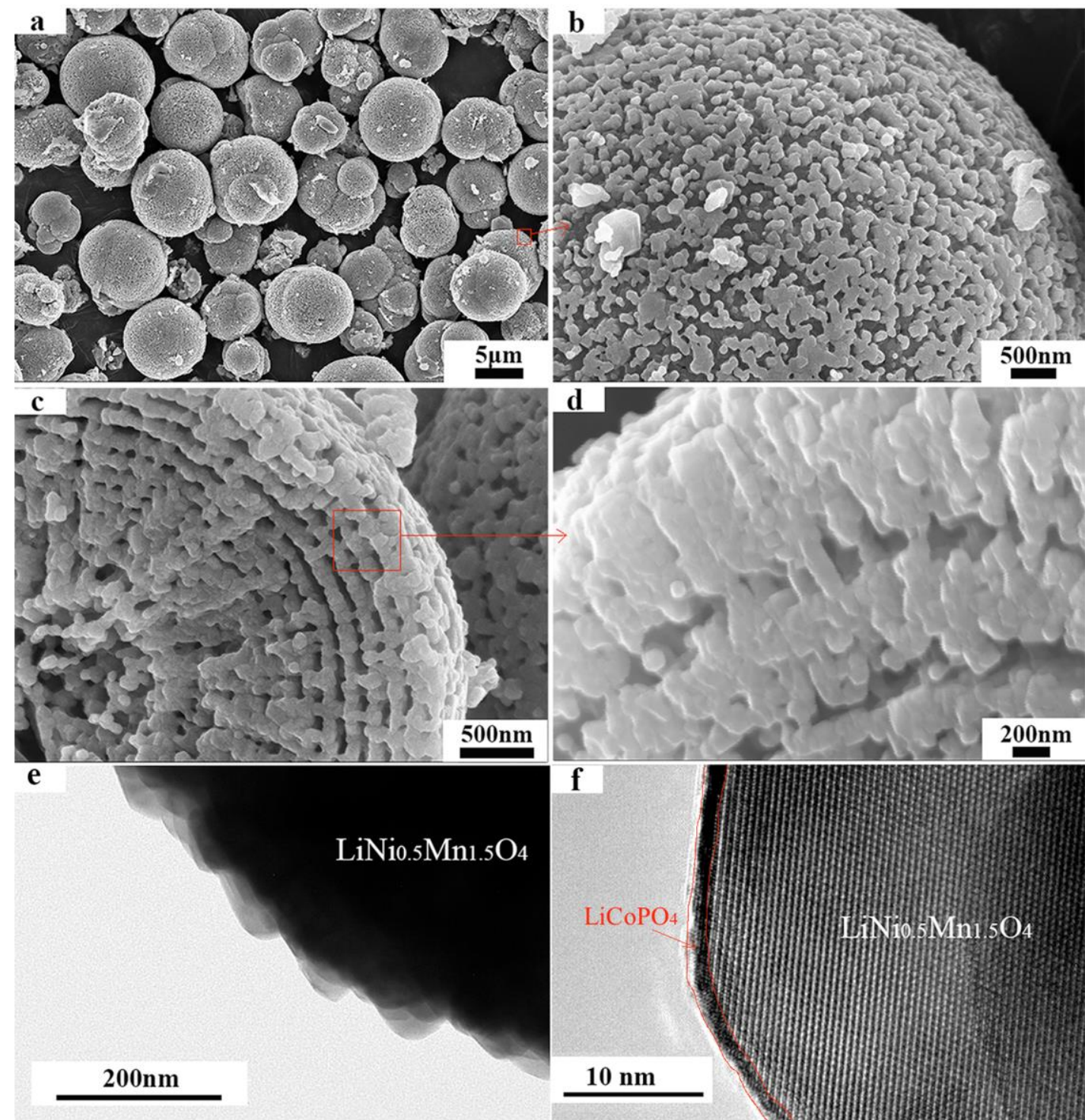

Figure 1 Schematic of synthesis method and morphology characterization of the

LNM@5\%LCP. (Schematic) Schematic of the preparation route for $\mathrm{LiCoPO}_{4}$ coated $\mathrm{LiNi}_{0.5} \mathrm{Mn}_{1.5} \mathrm{O}_{4}$; (a) SEM images of LNM@5\%LCP spherical particles; (b) the surface of LNM@5\%LCP spherical particles; (c, d) the sectional views after the particles were pressed in half; (e) TEM image of LNM@ $5 \%$ LCP sample and (f) the magnified TEM image. 


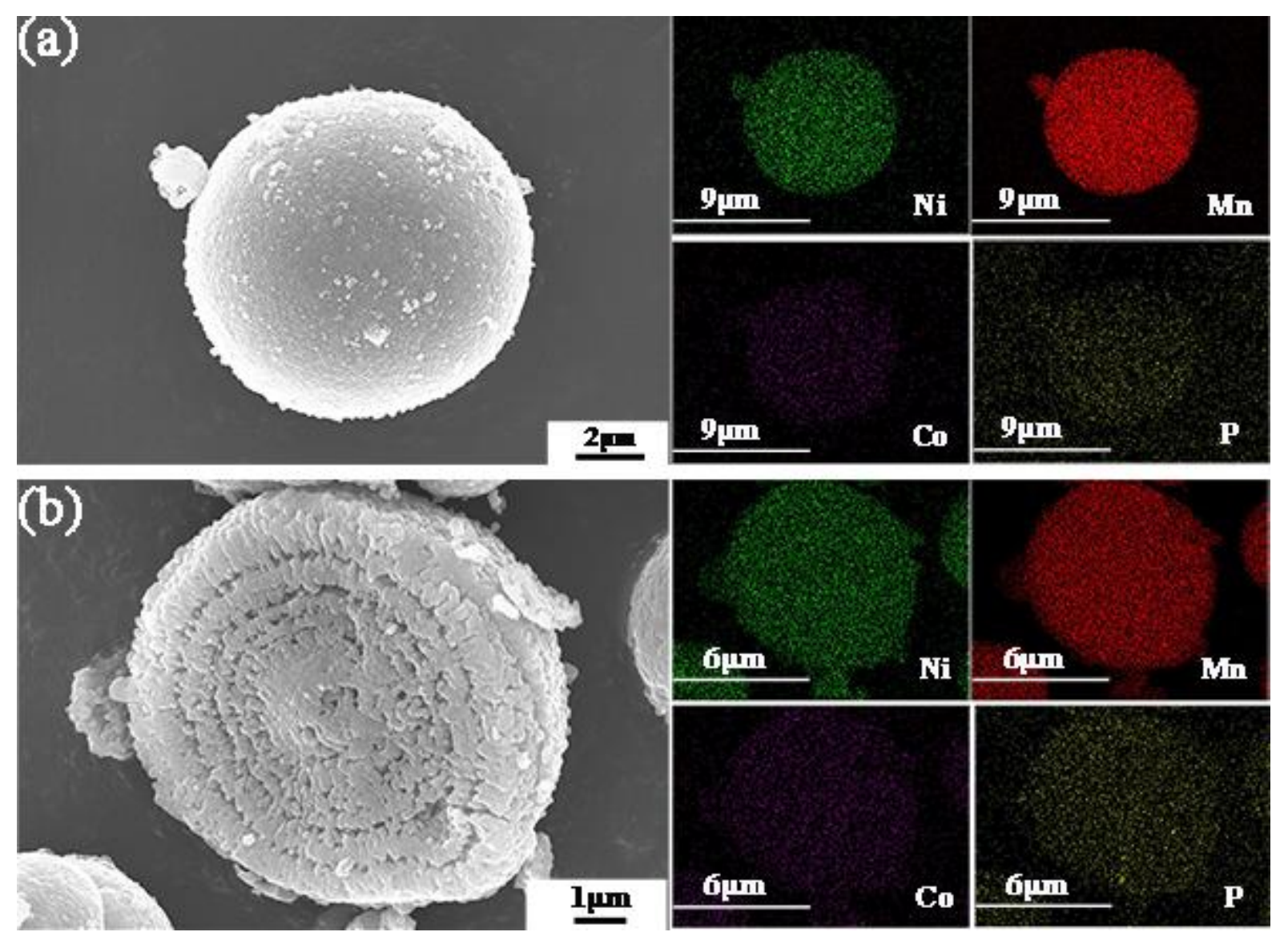

Figure 2 | Element distribution of the LNM@1\%LCPO. (a) SEM images and the relative EDS mapping in spherical view and (b) SEM images and the relative EDS mapping in cross sectional view after the particles were crashed into half. 


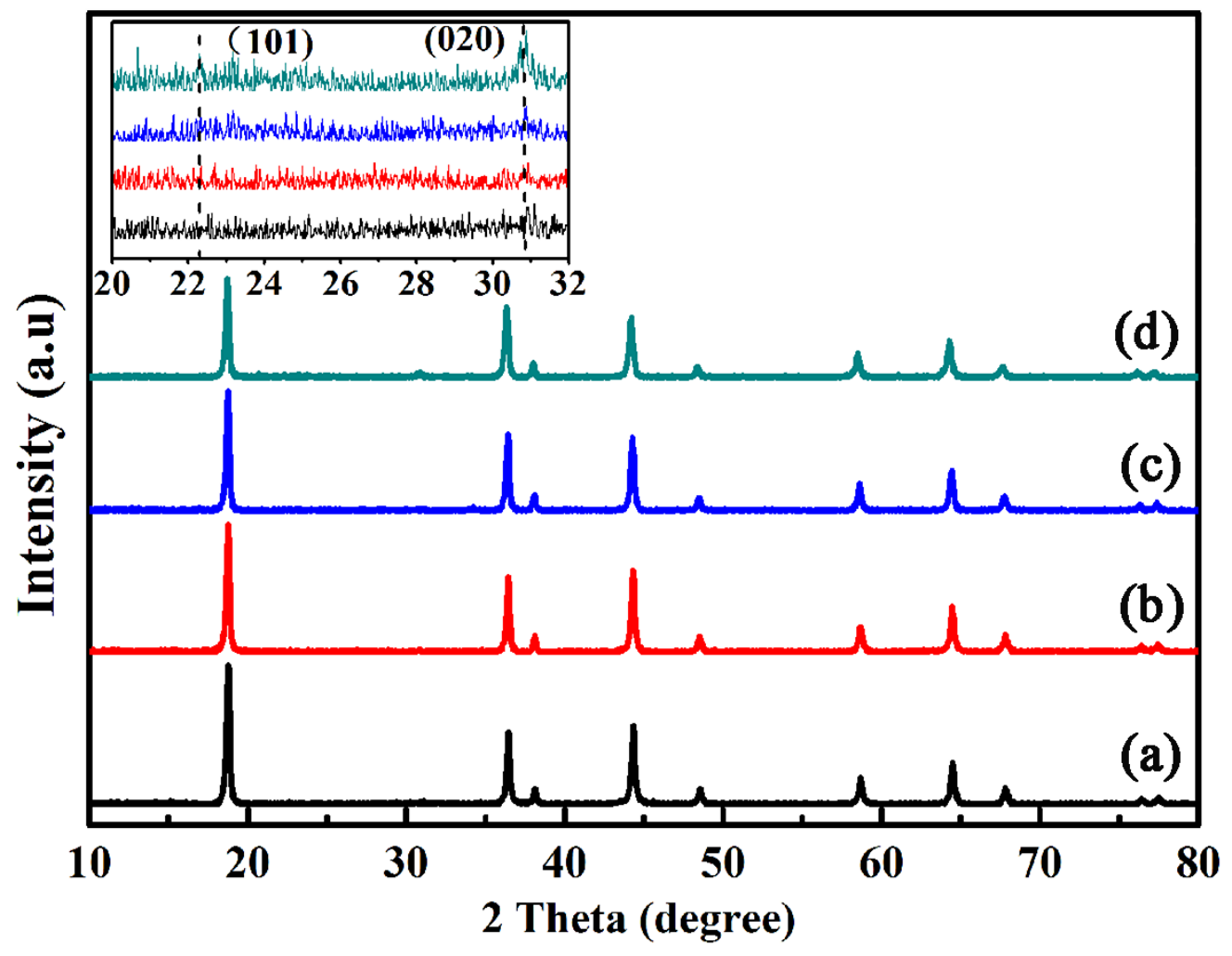

Figure 3 | XRD patterns. (a) LNM, (b) LNM@1\%LCP, (c) LNM@5\%LCP and (d) LNM@10\%LCP. The inset: enlarged patterns present the characterized peaks index by $\mathrm{LiCoPO}_{4}$ phase. 

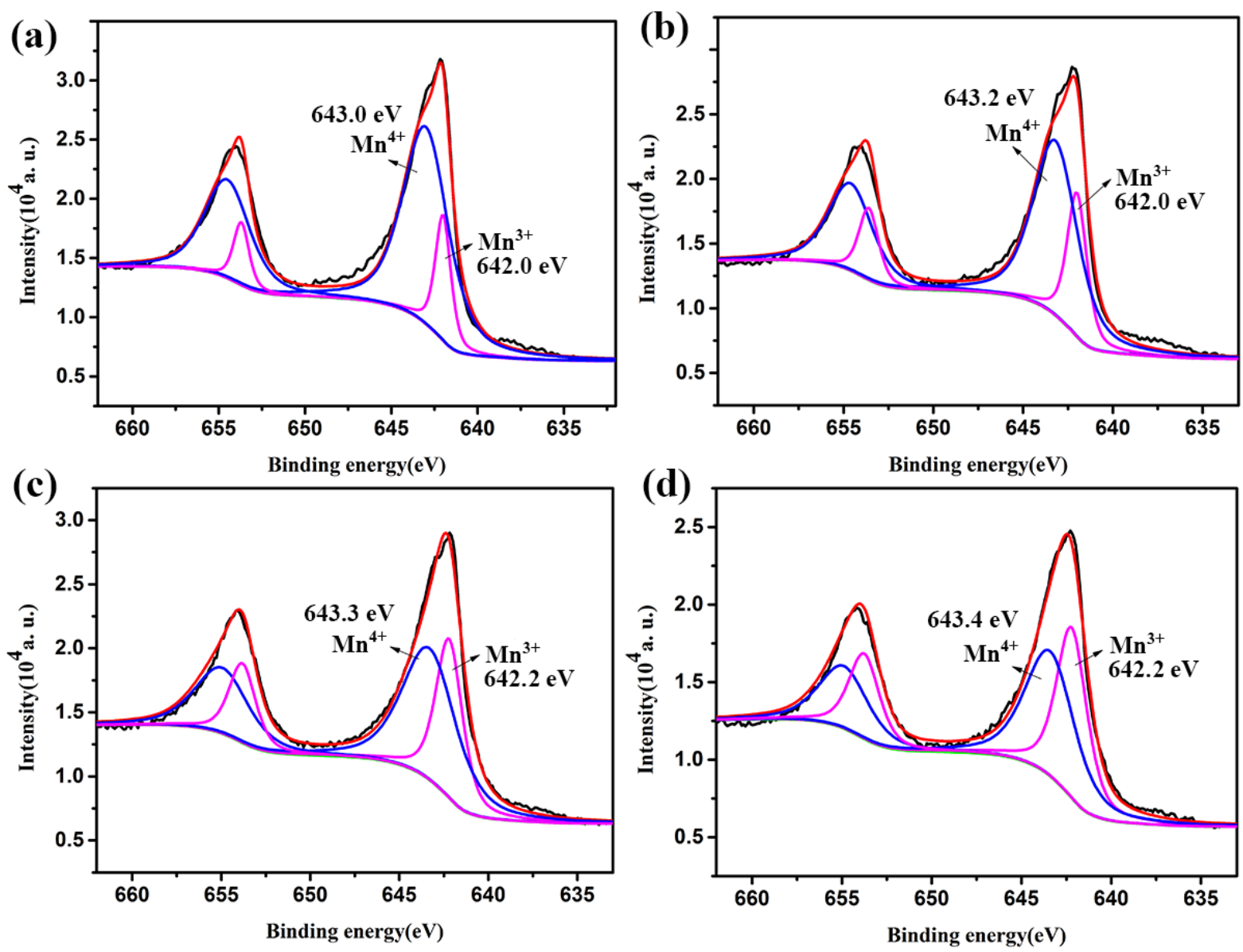

Figure 4 | High resolution XPS spectra in the region of Mn2p. (a) LNM, (b) LNM@1\%LCP, (c) LNM@5\%LCP and (d) LNM@ 10\%LCP, respectively. 

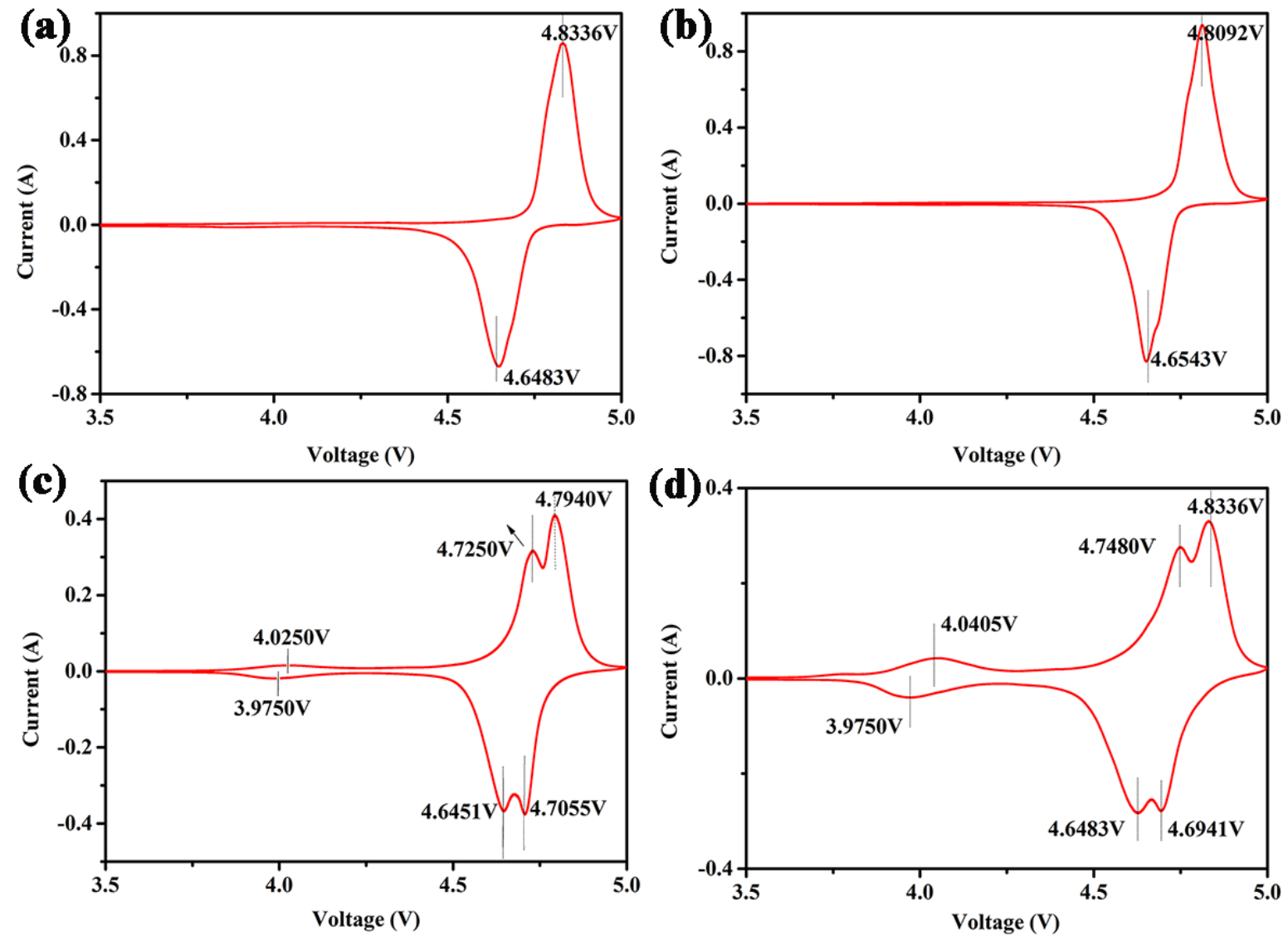

Figure 5 | Cyclic voltammograms. (a) LNM, (b) LNM@1\%LCP, (c) LNM@5\%LCP and (d) LNM@10\%LCP at a scan rate of $0.1 \mathrm{mV} \mathrm{s}^{-1}$. 

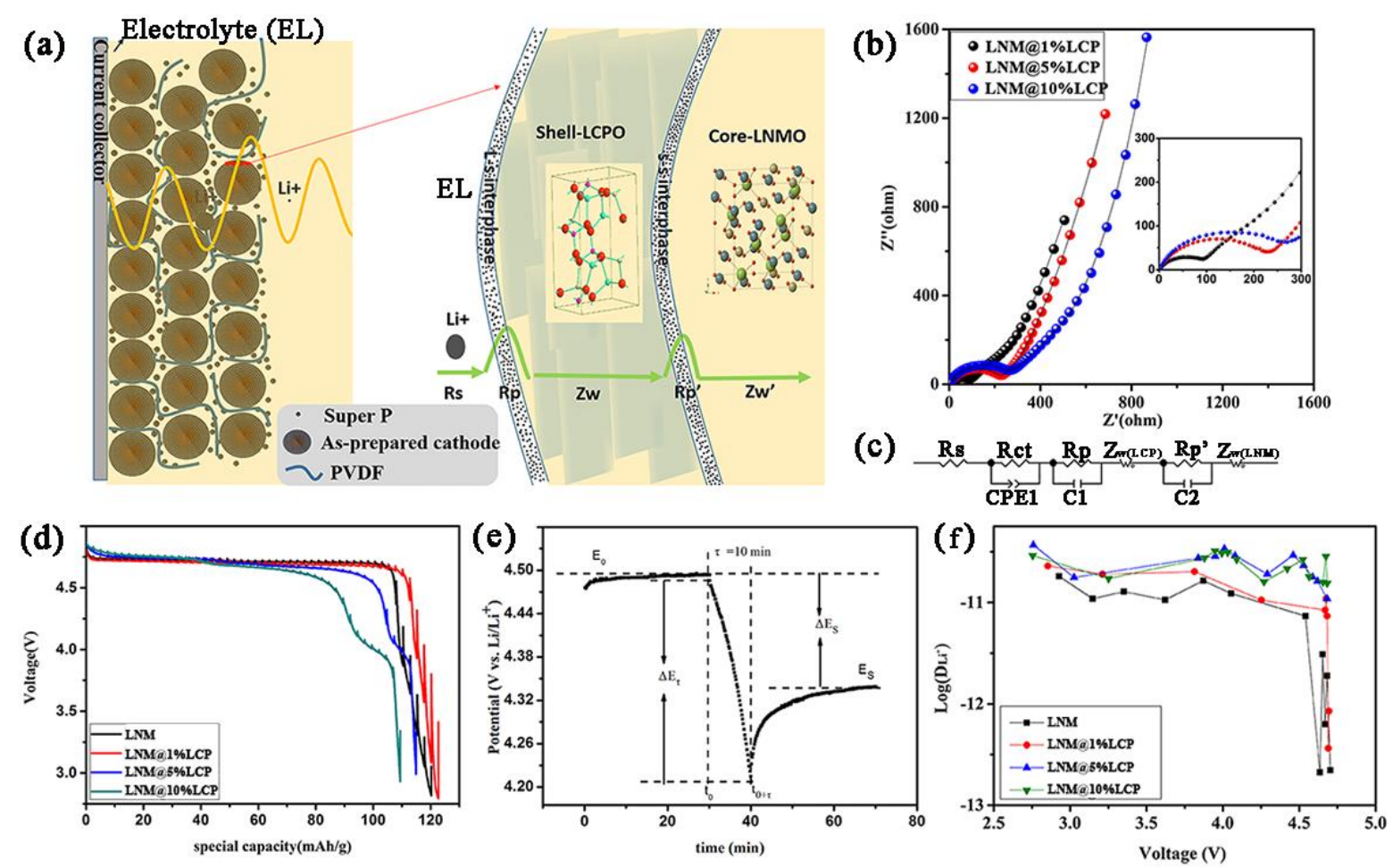

Figure 6 | (a) A schematic model illustrates the path of Li ions going through LNM@x\%LCP, (b) Nyquist plots of LNM@1\%LCP, LNM@5\%LCP and LNM@10\%LCP electrodes (inset is the high-frequency region of Nyquist plots) and (c) the equivalent circuit, (d) GITT curves of the four samples for the fourth discharge between $3 \mathrm{~V}$ and $5 \mathrm{~V}$ (rate: $0.1 \mathrm{C}$, time interval: 30 min), (e) t vs E profile for a single GITT titration, (f) diffusion coefficients of $\mathrm{Li}^{+}$in $\mathrm{LNM}$, LNM@1\%LCP, LNM@5\%LCP and LNM@10\%LCP, respectively. 

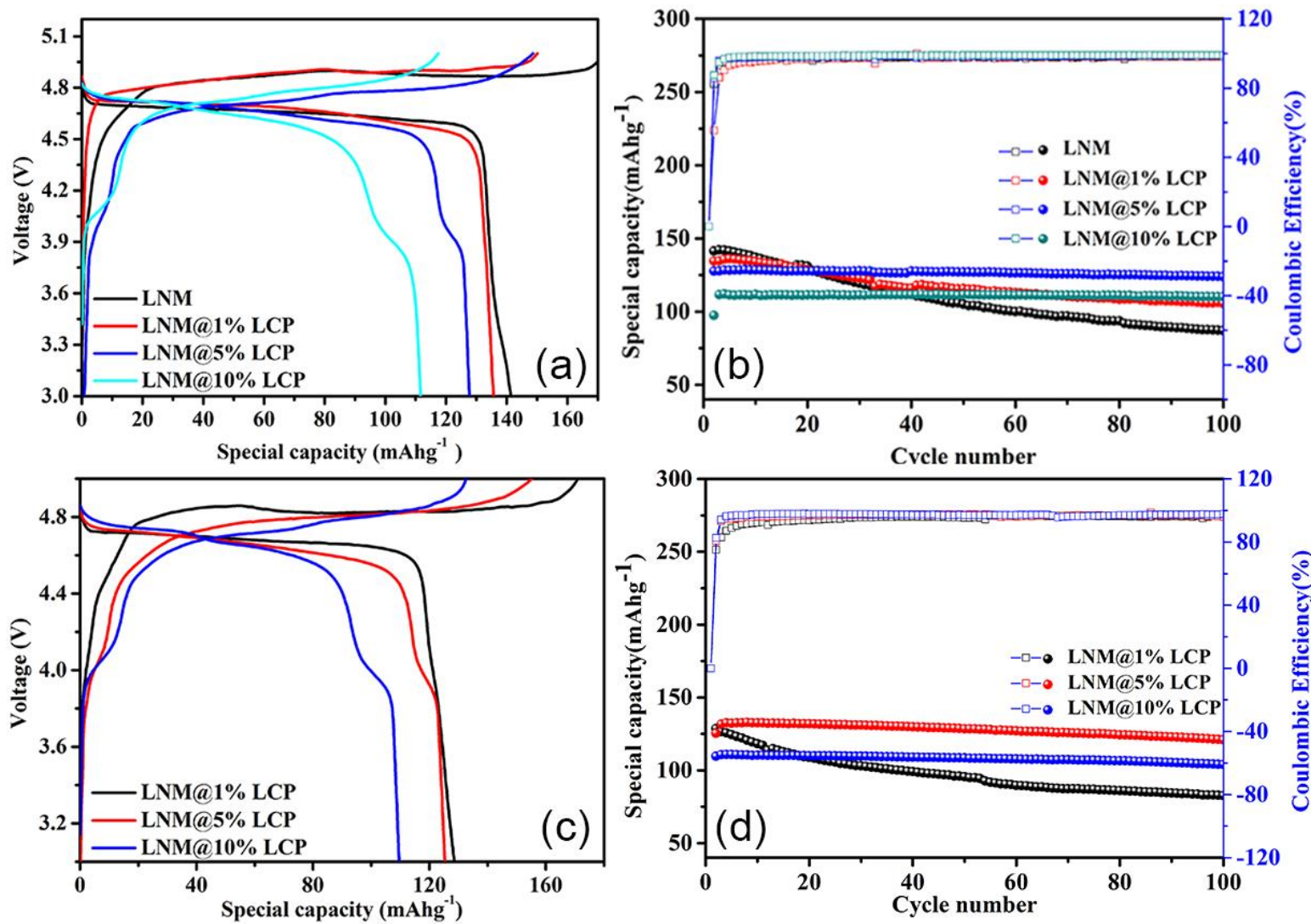

Figure 7 | Initial charge/discharge and cyclic profiles. (a, b) at $25{ }^{\circ} \mathrm{C}$ and $(\mathbf{c}, \mathbf{d})$ at $55^{\circ} \mathrm{C}$.

The current density is 0.5 C-rate. 

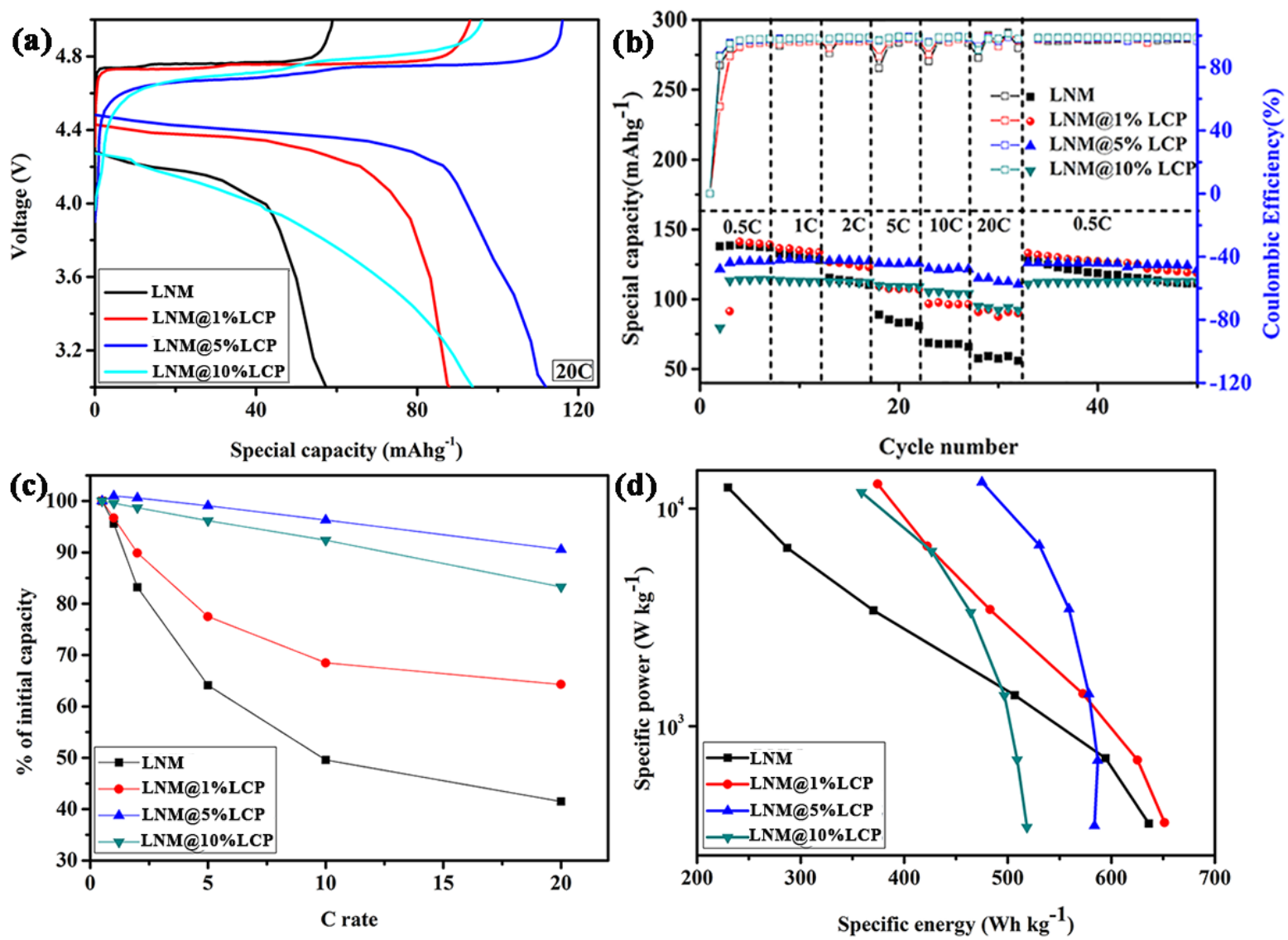

Figure 8 | (a) Initial charge/discharge profiles collected at 20 C-rate. (b) Rate capability of samples at various C-rates ranging from 0.5 to $20 \mathrm{C}$. (c) Evolution of normalized capacity as a function of discharge rate (d) and Ragone plot (d) for the four samples. 

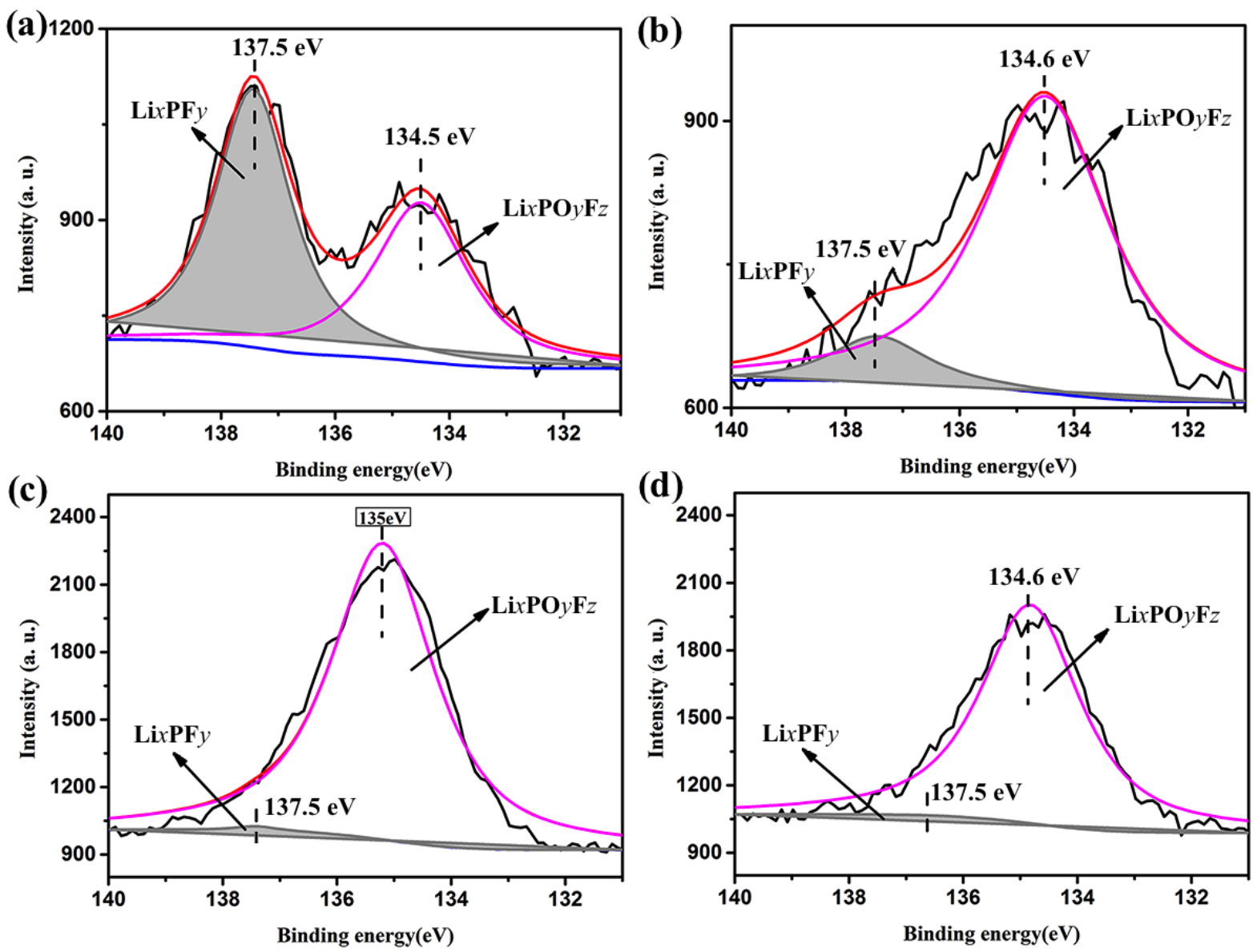

Figure 9 | High resolution XPS spectra in the region of P2p taken on the electrodes after 600 cycles at the current rate of 20 C. (a) LNM, (b) LNM@1\%LCP, (c) LNM@ $5 \%$ LCP and (d) LNM@10\%LCP 